\title{
Analisa Sifat-Sifat Serat Alam Sebagai Penguat Komposit Ditinjau Dari Kekuatan Mekanik
}

\author{
Rodiawan ${ }^{1 *}$, Suhdi², dan Firlya Rosa ${ }^{3}$ \\ ${ }^{1,2,3}$ Kampus Terpadu Universitas Bangka Belitung Balunijuk Bangka \\ rodiawan@yahoo.com, suhdi@ubb.ac.id, firlya@ubb.ac.id
}

\begin{abstract}
Abstrak
Salah satu pertimbangan dalam merencanakan bahan komposit adalah bagaimana agar material komposit yang akan di gunakan dalam suatu konstruksi dapat terdegradasi secara alami di alam. Penggunaan serat alam adalah solusi agar tujuan tersebut dapat tercapai. Penelitian ini bertujuan untuk menganalisa kekutan mekanik komposit dengan mengkombinasikan matrik polimer yang diperkuat dengan serat alam. Polimer yang digunakan adalah jenis resin YUKALAC 157 BQTN -EX dengan pengeras MEKPO. Penguat yang digunakan adalah masing-masing serat resam (dicranopteris linearis), serat ijuk (arenga Pennata) dan jerami padi. Setiap serat mendapatkan perlakuan perendaman pada $\mathrm{NaOH} 5 \%$ selama 2 jam. Standar uji menggunakan ASTM D638 untuk uji tarik dan D5941 untuk uji impak. Dari hasil pengujian diperoleh uji tarik yang paling tinggi adalah serat resam yaitu $26,8747 \mathrm{MPa}$, modulus elastisitas yang paling tinggi adalah serat jerami padi yaitu 4427,4030 $\mathrm{MPa}$, dan nilai regangan yang paling tinggi adalah serat resam yaitu $0,5482 \%$. Nilai kerja patah tertinggi adalah serat ijuk yaitu $18,1500 \mathrm{~J}$ dan nilai kekuatan impak tertinggi adalah serat ijuk yaitu $0,1120 \mathrm{~J} / \mathrm{mm}^{2}$.
\end{abstract}

Kata kunci : Komposit, serat resam, serta ijuk dan serat jerami padi

\section{Pendahuluan}

Komposit sudah lama diaplikasikan pada peralatan guna mempermudah kehidupan manusia. Bagian dari pesawat terbang, kendaraan bermotor, kapal laut dan perabotan rumah tangga merupakan aplikasi dari komposit.

Komposit merupakan kombinasi antara dua atau lebih material untuk mendapat sifat antara kedua atau lebih material tersebut. Komposit memiliki kelebihan antara lain ringan, kaku dan tahan lama. Unsur pembentuk komposit adalah matrik dan penguat. Matrik yang umum digunakan adalah polimer berbahan resin dan penguat serat sintetis berbahan dasar serat karbon.

Namun, penggunaan kedua jenis material diatas akan mengakibatkan masalah bagi lingkungan karena sulitnya terdegradasi oleh alam.

Penggunaan serat alami merupakan usaha yang dilakukan untuk mengurangi dampak lingkungan karena mudahnya terurai di lingkungan secara alami. Selain itu penggunaan serat alam ini mempunyai beberapa kelebihan antara lain: mudah didapat, jumlahnya berlimpah dan dapat diperbaharui.

Berlimpahnya jumlah serat resam (dicranopteris linearis), serat ijuk (arenga Pennata) dan jerami padi menjadi pertimbangan dalam penelitian ini. Perlakuan terhadap serat sebelum di cetak juga dilakukan guna mendapatkan sifat maksimum yang dapat di hasilkan dari komposit. Perlakukan terhadap masingmasing serat, yaitu perendaman pada air $\mathrm{NaOH} 5 \%$ selama 2 jam.

Penelitian ini bertujuan untuk mencari nilai maksimum terhadap sifat-sifat komposit dengan matrik polimer dan berpenguat ketiga serat alami diatas. 


\section{Tinjauan Teoritis}

Secara sederhana, komposit dapat diklasifikasikan berdasarkan gambar 1 .

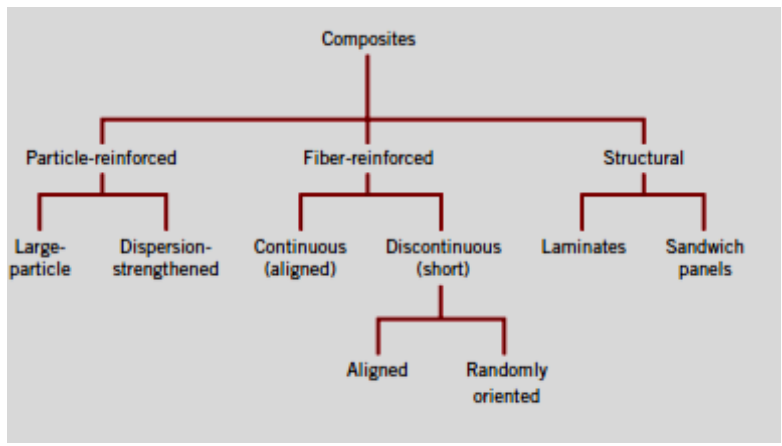

Gambar 1. Klalsifikasi [1]

Matrik berfungsi sebagai penahan serat agar menyatu, mendistribusikan beban dan juga berfungsi sebagai pembungkus. Penggunaan Matrik polimer mudah, karena suhu operasinya rendah dan matrik polimer ini dapat dibedakan menjadi dua yaitu, thermoset dan thermoplast.

Serat berfungsi sebagai penguat dan menyebabkan meningkatnya kekuatan tarik dan kekakuan. Pemilihan kriteria untuk memilih penguat fiber yang cocok adalah sebagai berikut: elongation, thermal stability, adhesion of the fiber and matrix, dynamic behavior, long-term behavior, and price and processing cost ${ }^{[2]}$

Resam (dicranopteris linearis) adalah jenis tumbuh pakis hutan yang hidup di daerah hutan sekunder (gambar 2). Tumbuhan ini biasanya tumbuh pada pada tanah liat yang buruk dan tumbuh menjalar ke atas pepohonan yang terdapat disekitarnya. Didalam tumbuhan resam terkandung zat tanduk, anti rayap, dan tahan terhadap udara lembab. Di dalam batang resam terdapat serat yang cukup kuat, ulet dan tahan lama, sehingga cocok digunakan sebagai serat alam untuk komposit.

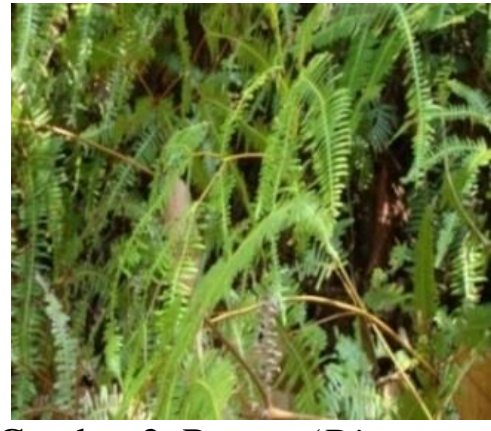

\section{Gambar 2. Resam (Dicranopteris} linearis)[3]

Serat ijuk (arenga pennata) adalah serat berwarna hitam yang dihasilkan dari pohon aren (gambar 3). Serat ini memiliki keistemewaan yaitu: tahan lama, tahan terhadap asam dan garam air laut dan memperlambat pelapukan kayu serta pencegah serangan rayap.

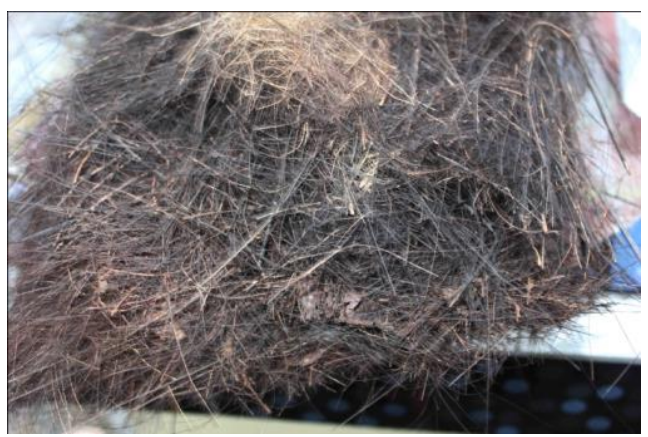

Gambar 3. Serat Ijuk [4]

Jerami padi adalah batang padi yang memiliki panjang $40-60 \mathrm{~cm}$ dan berupa ruas-ruas yang bagian dalamnya berongga (gambar 4). Syarat dalam pemilihan jerami padi adalah sebagai berikut: memiliki kekeringan yang cukup tinggi, nampak cemerlang, memiliki warna kuning cerah, ketebalan (diameter jerami) rata-rata sama dan memiliki berat yang rata-rata sama.

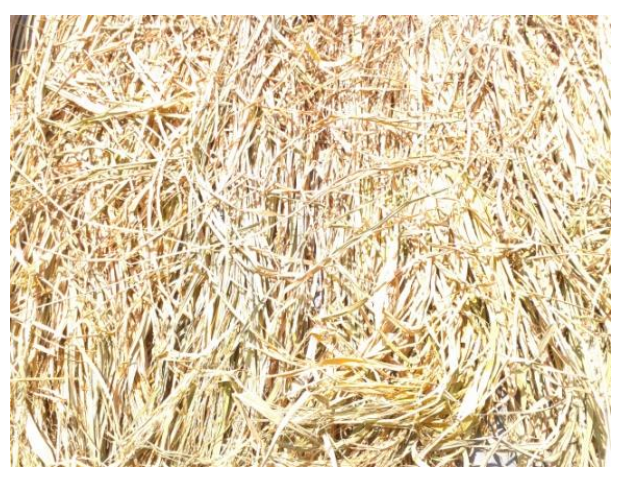

Gambar 4. Jerami padi [5] 
Uji tarik adalah suatu metode yang digunakan untuk menguji kekuatan suatu bahan/material dengan cara memeberikan gaya yang sesumbu, ukuran benda uji tarik sesuai dengan ukuran standar ASTM D638 (gambar 5) dan menggunakan mesin uji taik kapasitas $20 \mathrm{KN}$. Kekuatan tarik (tensile strength (persamaan 1), regangan tarik (persamaan 2) dan modulus elastisitas (persamaan 3).

$$
\begin{aligned}
& \sigma= \\
& \frac{F}{A} \ldots \ldots \ldots \ldots \ldots \ldots \ldots \ldots \ldots \ldots \ldots \ldots \ldots \ldots \ldots \ldots \ldots \\
&
\end{aligned}
$$
(N)

$\mathrm{A}=$ luas penampang awal sebelum ada pembebanan

$\varepsilon$

$=\frac{l_{i}-l_{0}}{l_{0}} \ldots \ldots \ldots \ldots \ldots \ldots \ldots \ldots \ldots$

$\varepsilon=$ Regangan

$l_{0=}$ Panjang awal $(\mathrm{mm})$

$\mathrm{l}_{\mathrm{i}}=$ panjang setela pembebanan $(\mathrm{mm})$

$E=\frac{\sigma}{\varepsilon}$

$=\frac{F \cdot l_{0}}{\Delta l \cdot A}$

$\mathrm{E}=$ Modulus Elastisitas (MPa)

$\sigma=$ kekuatan tarik $(\mathrm{MPa})$

$\varepsilon=$ Regangan

Uji impak adalah pengujian dengan pembebanan yang cepat (rapid loading) dengan ukuran standar ASTM D5941 (gambar 6) dan menggunakan mesin uji impak yang memiliki massa bandul $2,5 \mathrm{~kg}$, panjang bandul $0,4 \mathrm{~m}$ serta sudut awal bandul sebelum jatuh $150^{\circ}$. Kerja patah (persamaan 4) dan Kekuatan impak (persamaan 5).

$$
\begin{aligned}
& W=G \cdot g \cdot R(\operatorname{Cos} \beta-\operatorname{Cos} \alpha \ldots \ldots \ldots(4) \\
& \mathrm{W}=\operatorname{Kerja} \text { patah }(\mathrm{J}) \\
& \mathrm{G}=\text { Beban yang digunakan }(\mathrm{kg}) \\
& \mathrm{g}=\text { Percepatan grafitasi bumi }\left(9,81 \mathrm{~m} / \mathrm{s}^{2}\right)
\end{aligned}
$$

$\mathrm{R}=$ Panjang lengan ayun (m)

$\beta=$ Sudut jatuh $\left(^{\circ}\right)$

$\alpha=$ Sudut awal $\left({ }^{\circ}\right)$

$H I=\frac{W}{A_{0}}$

$\mathrm{HI}=$ Harga impak $\left(\mathrm{J} / \mathrm{mm}^{2}\right)$

$\mathrm{W}=$ Kerja patah $(\mathrm{J})$

$\mathrm{A}_{0}=$ Luas penampang $\left(\mathrm{mm}^{2}\right)$

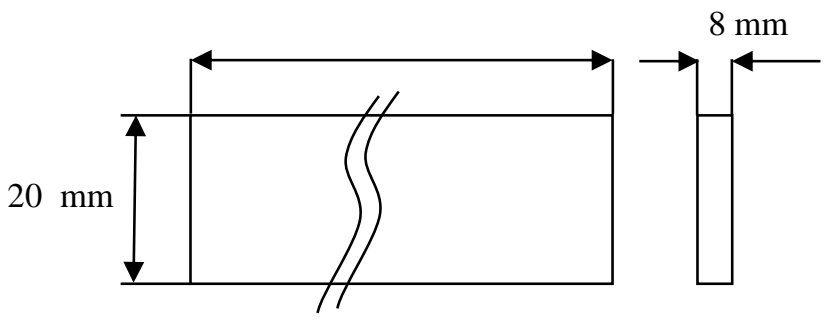

Gambar 5. Ukuran benda uji tarik standar ASTM D638

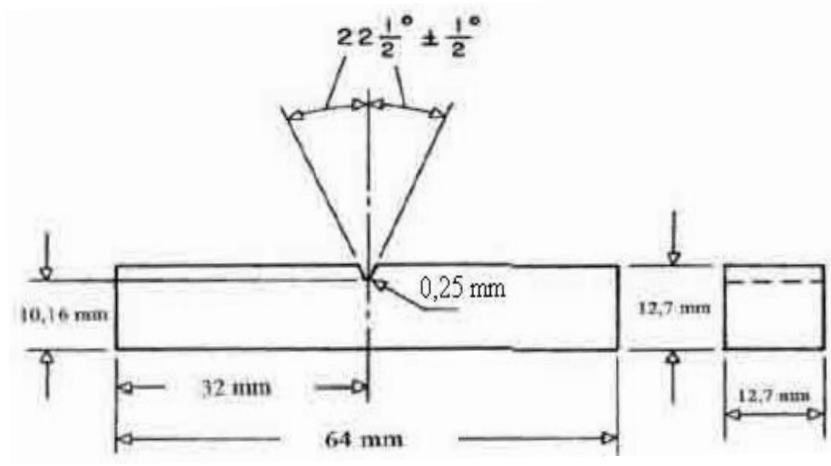

Gambar 6. Ukuran benda uji impak standar ASTM D5941

\section{Metode Penelitian}

Pengolahan data primer yang telah diuji coba dengan tahapan sebagai berikut:

a. Pengambilan dan pengolahan data

b. Analisa data

\section{Hasil dan Pembahasan}

Saputra (2015), Widiarto (2014), dan Suliyanto (2015) melakukan penelitian terhadap komposit serat resam (dicranopteris linearis), serat ijuk (arenga pennata) dan jerami padi dengan ukuran sampel uji $20 \times 8 \times 400 \mathrm{~mm}$ dengan perendaman $\mathrm{NaOH} 2$ jam [6]. Dari hasil percobaan, nilai kekuatan tarik tertinggi 
adalah serat resam sebesar 21,5753 $\mathrm{MPa}$. (gambar 7).

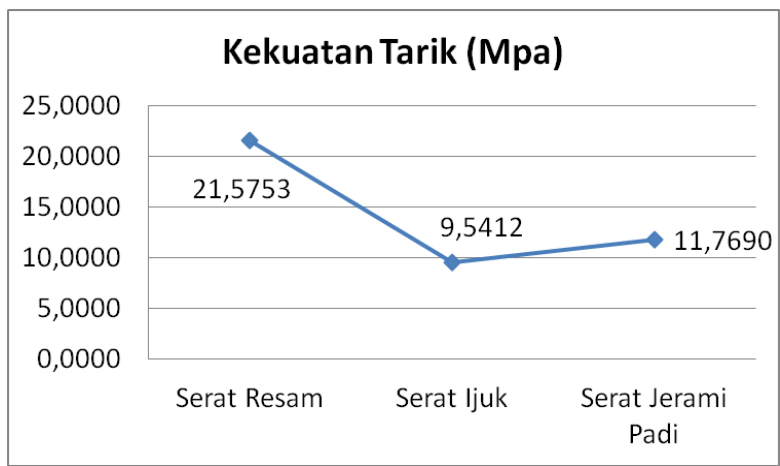

Gambar 7. Kekuatan tarik

Nilai Modulus Elastisitas tertinggi adalah serat jerami padi sebesar 4427,4030 MPa. (gambar 8).

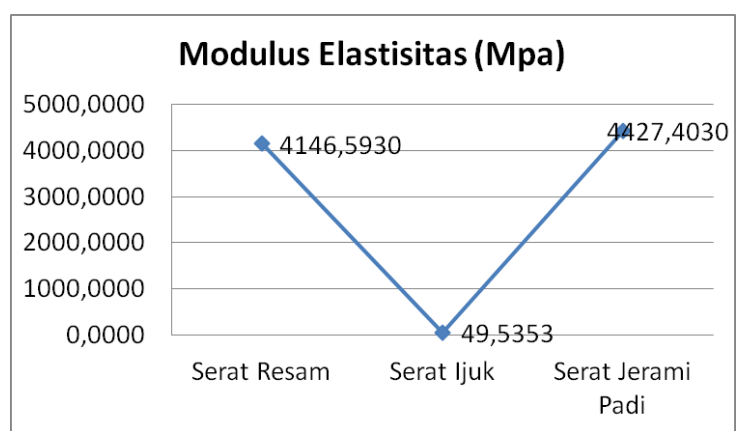

Gambar 8. Modulus Elastisitas

Nilai regangan tertinggi adalah serat resam $0,6616 \%$. (gambar 9).

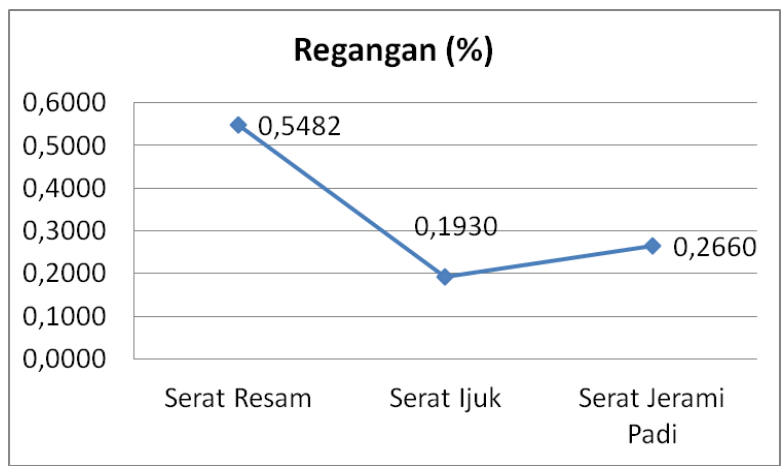

Gambar 9. Regangan

Nilai kekuatan patah tertinggi adalah serat ijuk sebesar 18,16 J. (gambar 10).

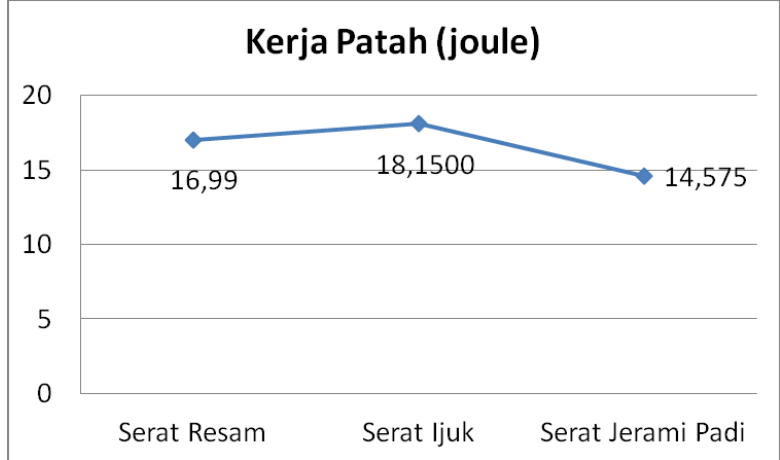

Gambar 10. Kerja patah tanpa rendaman.

Nilai kekuatan impak tertinggi adalah serat ijuk sebesar $0,1120 \mathrm{~J} / \mathrm{mm}^{2}$ (gambar 11).

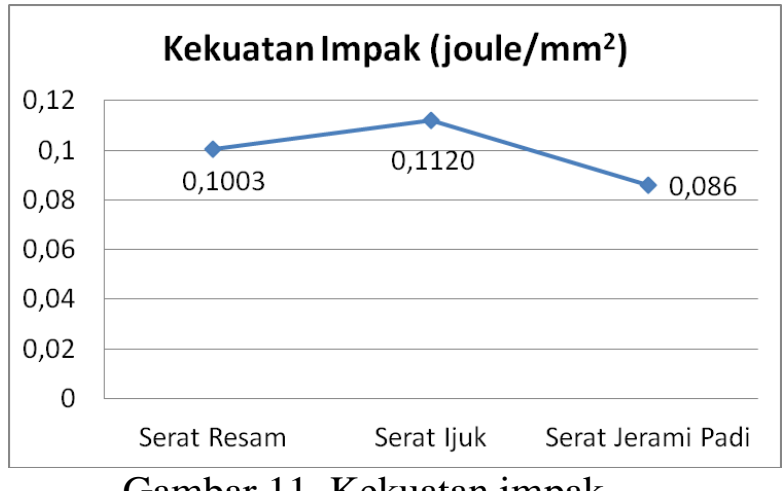

Gambar 11. Kekuatan impak.

\section{Kesimpulan}

Dari 3 bahan yang digunakan dapat ditarik kesimpulan bahwa serat resam memiliki kekuatan tarik dan regangan tertinggi dibandingkan dengan bahan serat lainnya, namun nilai modulus elastisitas lebih rendah dibandingkan dengan bahan serat jerami padi tetapi lebih tinggi dibandingkan dengan serat ijuk. Hal ini berbanding terbalik dengan kekuatan patah dan kekuatan impak. Serat ijuk memiliki kekuatan patah dan kekuatan impak tertinggi dibandingkan dengan bahan serat resam maupun serat jerami padi.

\section{Referensi}

[1] Callister Jr, William D, Materials Science and Engineering, an Introduction, Sixth Edition, John Willey \& Sons Ltd., Singapore, 2003.

[2] Riedel, U., Nickel, J., Applications of natural composites for constructive 
parts in aerospace, automobiles, and other areas, Wiley-VCH Verlag $\mathrm{GmbH}$ \& Co. KgaA, 2005.

[3] Saputra E, Pemanfaatan Serat Ijuk (Arenga pinnata) Sebagai Alternatif Pengganti Serat Kaca (Fiber Glass) Untuk Pembuatan Spoiler Pada Mobil Listrik Tarsius X2 Universitas Bangka Belitung. Tugas Akhir Jurusan Teknik Mesin. Universitas Bangka Belitung, 2014.

[4] Leo Taufan W, Pengaruh Perlakuan Seat Batang Resam (DICRANOPTERIS LINEARIS)

Terahadap Kekeuatan Mekanik Pada Pembuatan Material Komposit. Tugas Akhir Jurusan Teknik Mesin. Universitas Bangka Belitung, 2015.

[5] Suliyanto, Analisa Sifat Mekanik Material Komposit yang Terbuat dari Bahan Jerami Padi dan Resin, Tugas Akhir Jurusan Teknik Mesin, Universitas Bangka Belitung, 2015.

[6] Mayati B., Sonief A.A., \& Wahyudi S., Pengaruh Alkalisasi Komposit Serat Kelapa-Poliester Terhadap Kekuatan Tarik, Jurnal Rekayasa Mesin Vol.2, No. 2 : 123-129, 2011. 